\title{
Periodic and Random Substrate Textures for Liquid Phase Crystallized Silicon Thin-Film Solar Cells
}

\author{
Grit Köppel ${ }^{\mathrm{a}}$, Daniel Amkreutz ${ }^{\mathrm{a}}$, Paul Sonntag ${ }^{\mathrm{a}}$, Guangtao Yang ${ }^{\mathrm{b}}$, René van Swaaij ${ }^{\mathrm{b}}$, Olindo Isabella ${ }^{\mathrm{b}}$, \\ Miro Zeman ${ }^{\mathrm{b}}$, Bernd Rech ${ }^{\mathrm{a}}$, and Christiane Becker ${ }^{\mathrm{a}}$ \\ ${ }^{a}$ Helmholtz-Zentrum Berlin für Materialien und Energie GmbH, Kekuléstr. 5, D-12489 Berlin, Germany \\ ${ }^{b}$ Laboratory of Photovoltaic Material and Device, Delft University of Technology, P.O. Box 5031, Delft \\ 2600 GA, The Netherlands
}

\begin{abstract}
A major limitation in current liquid phase crystallized (LPC) silicon thin-film record solar cells are optical losses caused by their planar glass-silicon interface. In this study, silicon is grown on nanoimprinted periodically as well as on randomly textured glass substrates and successfully implemented into state-of-the-art LPC silicon thin-film solar cells. Compared to an optimized planar reference device, both textures enhance absorption of light. Interlayer and process optimization allowed achieving a material quality comparable to the planar reference device. On the random texture an open-circuit voltages above $630 \mathrm{mV}$ was obtained as well as an external quantum efficiency exceeding the planar reference device by $+3 \mathrm{~mA} / \mathrm{cm}^{2}$.
\end{abstract}

Index Terms - silicon, thin-film solar cells, light management, absorption enhancement.

\section{INTRODUCTION}

Recently, a new in-house record of $12.1 \%$ efficiency for a $10-\mu \mathrm{m}$ thick liquid phase crystallized (LPC) silicon thin film solar cell on glass has been achieved by texturing the silicon absorber backside as well as reducing reflection losses at the air-facing surface [1]. In this cell design the optical absorption potential is not fully tapped due to losses at the planar glasssilicon interface. Hence, effective measures for light management are needed at this interface to further increase photo-generated current densities. It has been demonstrated for other thin-film silicon solar cell types [2]-[5] that an enhancement of cell efficiencies ensues. However, the challenge is to identify structures that increase the incoupling of light while at least maintaining the electronic material quality of the silicon absorber layer [6]-[10].

Texturing glass substrates by nanoimprint lithography using high-temperature stable sol-gels has proven to be a suitable method for texturing the glass-silicon interface in LPC silicon solar cells [11], [12]. A smooth random $\mathrm{ZnO}: \mathrm{Al}$ (AZO) texture as well as a periodic U-shaped texture with an aspect ratio of 0.5 have been transferred to glass substrates. On one hand, the smooth AZO texture maintained the electronic silicon material quality but did not significantly enhance light incoupling into the cell. On the other hand, the high aspect ratio U-shaped texture remarkably enhanced the optical properties of the cells but disturbed the silicon material quality resulting in reduced quantum efficiencies [11]. Recently, a hexagonal sinusoidal structure ('Sine') with an aspect ratio of 0.2 has shown to be a balanced compromise between these two extreme cases [12].
For this device, the anti-reflective effect of the glass-silicon texture as well as the light-trapping effect of the double-sided textured absorber layer led to an enhancement of external quantum efficiency in the short and long wavelength range, respectively. However, in the wavelength range between $400 \mathrm{~nm}$ and $700 \mathrm{~nm}$ the conversion efficiency declined due to recombination losses caused by insufficient interface passivation.

Another approach in this work is to implement modulated surface textured ('MST') glass substrates [13]. These glasses have already been integrated successfully into $3-\mu \mathrm{m}$ thick $\mu \mathrm{c}-$ $\mathrm{Si}: H$ solar cells, enabling a cell efficiency above $10 \%$ [14]. These random textures have been chosen due to their for an enhanced material quality promising smoother texture flanks compared to the sinusoidal texture.

The optical properties of both texture types, the periodic sinusoidal and random MST texture, have been studied experimentally in a preceding conference proceeding [15]. By systematically varying every layer the entire sample stack has been optimized regarding its anti-reflection ability. Compared to an optimized planar reference device, a reduction of reflection losses by $-3.5 \%$ (absolute) on the random and by 9.4\% (absolute) on the periodic texture has been achieved in the wavelength range of interest (section $\mathrm{A}$ and $\mathrm{B}$ ). In enhancement of the conference proceedings, the experimental study of the optical properties is complemented by measurements of the electronic properties of the MST texture from which the quality of the textured silicon absorber layer can be inferred (section C).

\section{EXPERIMENTAL}

As glass substrates, $0.7-\mathrm{mm}$ and $1.1-\mathrm{mm}$ thick Corning Eagle $\mathrm{XG}^{\mathrm{TM}}$ glasses have been used. After periodical or random texturing, the substrates were coated with a $250-\mathrm{nm}$ $\mathrm{SiO}_{\mathrm{x}}$ layer acting as diffusion barrier against substrate impurities. As periodic texture, a $750-\mathrm{nm}$ pitched hexagonal sinusoidal structure has been transferred to glass substrates using nanoimprint lithography in combination with a hightemperature stable sol-gel. Details on the process can be found in [12]. On the other hand, differently sized random textures were transferred into the substrates by wet chemical etching using sacrificial layers. Depending on the sacrificial layer type 
differently sized crater-like features can be achieved: an ITO induced process results in a morphology with typical average lateral features size of $15 \mu \mathrm{m}$ ('IIT') and a $\mathrm{ZnO}: \mathrm{Al}$ induced process results in a morphology with typical average lateral features size of $2 \mu \mathrm{m}$ ('ZIT') [16]. In addition, both textures can be superimposed to produce a modulated surface texture ('MST') [14].

These textured substrates as well as planar reference substrates have subsequently been coated with $\mathrm{SiN}_{\mathrm{x}}$ and $\mathrm{SiO}_{\mathrm{x}}$ layers, where the $\mathrm{SiN}_{\mathrm{x}}$ layer provides anti-reflective properties while the $\mathrm{SiO}_{\mathrm{x}}$ acts as a passivation layer as well as wetting agent for silicon during liquid phase crystallization [17], [18]. For optical optimization both interlayer thicknesses as well as the thickness of the subsequently deposited silicon absorber layer have been varied between $50 \mathrm{~nm}$ and $80 \mathrm{~nm}$ for the $\mathrm{SiN}_{\mathrm{x}}$ layer, $5 \mathrm{~nm}$ to $20 \mathrm{~nm}$ for the $\mathrm{SiO}_{\mathrm{x}}$ layer and $5 \mu \mathrm{m}$ to $30 \mu \mathrm{m}$ for the silicon absorber layer. The silicon absorber layers are deposited by electron beam evaporation at a heater temperature of $600^{\circ} \mathrm{C}$ and capped with a 200-nm thick $\mathrm{SiO}_{x}$ layer. Afterwards the samples were crystallized by scanning a line-shaped $\mathrm{CW}$ laser emitting at $808 \mathrm{~nm}$ over the preheated substrate $\left(700{ }^{\circ} \mathrm{C}\right)$ with a constant velocity of $3 \mathrm{~mm} / \mathrm{s}$. By means of this capping layer the substrate texture is preserved at the top of the silicon absorber layer after liquid phase crystallization resulting in a double-sided textured silicon absorber layer [19]. The capping layer is removed by wet chemical etching in buffered-HF for nine minutes. On both textured glasses as well as on planar reference substrates 15$\mu \mathrm{m}$ thick LPC n-doped silicon thin-film solar cells with a doping concentration of $\sim 5 \cdot 10^{16} \mathrm{~cm}^{-3}$ have been prepared as described in [20], there denoted as test structure. A schematic solar cell device structure as well as atomic force microscope (AFM) images of sinusoidal and MST textured glass substrates are depicted in Fig. 1.
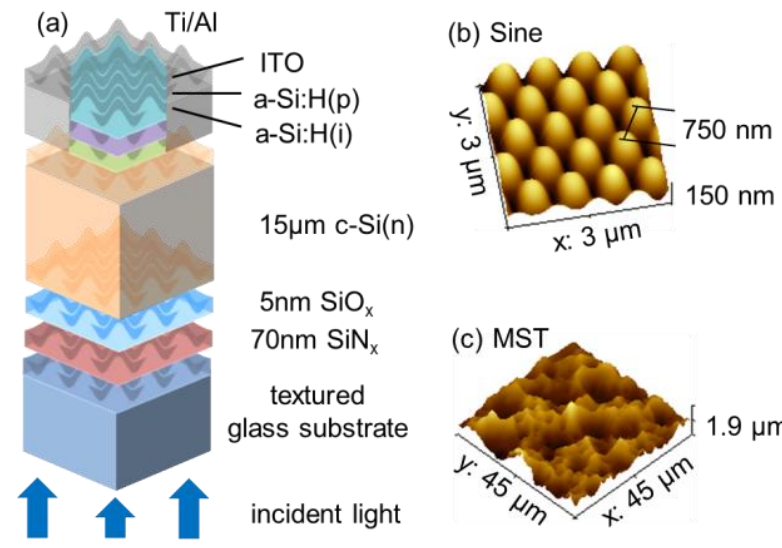

Fig. 1. (a) Schematic of the solar cell device structure. AFM images of textured glass surfaces patterned with (b) a hexagonal sinusoidal texture ('Sine') and (c) a modulated surface texture (MST).
Optical analysis has been conducted using a Perkin Elmer LAMBDA 1050 spectrometer featuring an integrating sphere. Average reflectance values have been calculated for a wavelength range of $300 \mathrm{~nm}$ to $600 \mathrm{~nm}$, the substantial wavelength range for anti-reflective properties at the glasssilicon interface. For external quantum efficiency (EQE) measurements a custom-made setup was used, containing a probing beam size of $3 \mathrm{~mm} \times 2 \mathrm{~mm}$ and LED-based bias-light. Open-circuit voltages $\left(\mathrm{V}_{\mathrm{oc}}\right)$ were obtained by Suns- $\mathrm{V}_{\mathrm{oc}}$ measurements carried out at room temperature using a Suns$\mathrm{V}_{\text {oc }}$ unit of a WCT-100 photo-conductance lifetime tool by Sinton Instruments. Surface morphology determination of the structures was realized using a Park Systems XE-70 AFM (Fig. $1 \mathrm{~b}+\mathrm{c}$ ).

\section{RESULTS AND DISCUSSION}

Here, we implement periodic and random textures into stateof-the-art LPC silicon thin-film absorber layers in order to address reflection losses at the glass-silicon interface and enhance solar cell performance. For this purpose the structure type, the thicknesses of the $\mathrm{SiN}_{\mathrm{x}} / \mathrm{SiO}_{\mathrm{x}}$ interlayer stack as well as the silicon absorber thicknesses are varied (section A). Based on these results optimal thicknesses are chosen and analyzed regarding their optical properties (section B) and opto-electrical (section C) performance in LPC-Si solar cells on glass.

\section{A. Texture, Interlayer and Absorber Thickness Variation}

In Fig. 2 the optical properties of both texture types are compared regarding their anti-reflection potential in state-ofthe-art 10- $\mu \mathrm{m}$ thick LPC silicon absorber layers with a $\mathrm{SiN}_{\mathrm{x}}$ $70 \mathrm{~nm} / \mathrm{SiO}_{\mathrm{x}} 10 \mathrm{~nm}$ interlayer stack [20]. The sample stack under investigation is schematically depicted as an inset with a color code according to Fig. 1a and with a horizontal arrow indicating which layer has been varied.

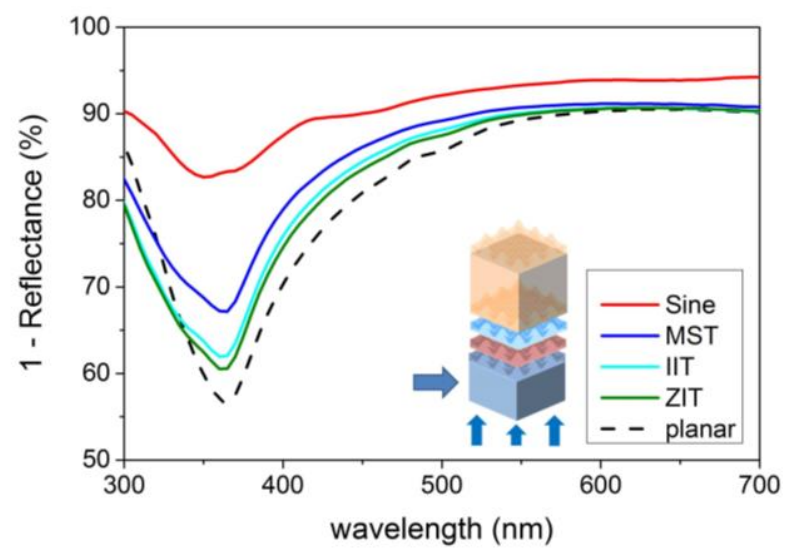

Fig. 2. Reflectance data ( $R$, plotted as 1-R) of a planar reference (black, dashed), different random textures with large features (IIT, cyan), small features (ZIT, green) and a combination of both (MST, blue) as well as a hexagonal sinusoidal texture (Sine, red). 
Compared to a planar reference (black, dashed line) with optimized interlayer stack, all textures provide additional antireflective properties (solid lines) over the entire wavelength range. The highest reflection reduction is found for the periodic sinusoidal texture (Sine, red). Comparing the different random textures with large features (IIT, cyan), small features (ZIT, green) and combined texture (MST, blue) the largest reflection reduction is found for the combined MST texture. Therefore, the MST texture is chosen for further analysis as random texture.

Incident light with wavelengths longer than $600 \mathrm{~nm}$ reaches the backside of the absorber and is either transmitted without being absorbed or scattered back. Hence, the light scattering effect of the double-sided textured absorber layer becomes visible and both light trapping effects superimpose. Therefore, the analysis of the anti-reflective effect is restricted to shorter wavelengths than $600 \mathrm{~nm}$. There, average reflection losses of the planar reference of $24.2 \%$ are reduced by $-7.1 \%$ (absolute) for the MST texture (blue) and $-14.0 \%$ (absolute) for the sinusoidal texture (red), which was chosen based on simulations of Lockau et al. predicting optimum anti-reflective properties in thin-film LPC silicon devices for a hexagonal sinusoidal texture [21].

To find optimum optical properties the subsequently deposited $70 \mathrm{~nm} \mathrm{SiN}, 10 \mathrm{~nm} \mathrm{SiO}_{\mathrm{x}}$ and $10 \mu \mathrm{m} \mathrm{Si}$ absorber layer have been varied systematically by keeping two layer thicknesses fixed and varying one layer thickness (Fig. 3). A schematic sample stack is depicted as inset, where the varied layer is highlighted by a horizontal arrow.

For wavelength shorter than $450 \mathrm{~nm}$ reflection losses increase with increasing $\mathrm{SiN}_{\mathrm{x}}$ interlayer thickness (Fig. 3a) resulting in the highest reflection losses for the thickest barrier ( $80 \mathrm{~nm}$, orange). However, for longer wavelength this trend inverts and the highest reflection losses are found for the thinnest barrier $(50 \mathrm{~nm}$, dark blue) while all other barrier thicknesses are about equal without clear trend. While the $60 \mathrm{~nm}$ barrier (purple) features slightly lower reflection losses than the $70 \mathrm{~nm}$ barrier (red) for wavelength smaller than $500 \mathrm{~nm}$, for longer wavelength the reflection losses of the thicker barrier are slightly lower, such that overall no clear difference between these two $\mathrm{SiN}_{\mathrm{x}}$ barrier thicknesses can be found. Hence, both medium interlayer thicknesses $(60 \mathrm{~nm}$ and $70 \mathrm{~nm}$ ) are suited for implementation into LPC-Si solar cell devices.

For the $\mathrm{SiO}_{\mathrm{x}}$ layer thickness variation (Fig. 3b) reflection losses increase with increasing $\mathrm{SiO}_{\mathrm{x}}$ thickness for wavelength shorter than $550 \mathrm{~nm}$. For longer wavelength no difference between the different $\mathrm{SiO}_{\mathrm{x}}$ layer thicknesses is found. Therefore, the thinnest $5 \mathrm{~nm} \mathrm{SiO}$ x barrier (red) is favorable for implementation into LPC-Si solar cell devices. Lower $\mathrm{SiO}_{x}$ thicknesses were not evaluated since they are known to degrade the electronic properties of a solar cell [20].

In order to compare different silicon absorber layer thicknesses (Fig. 3c) on sinusoidal (diamond, red) and on
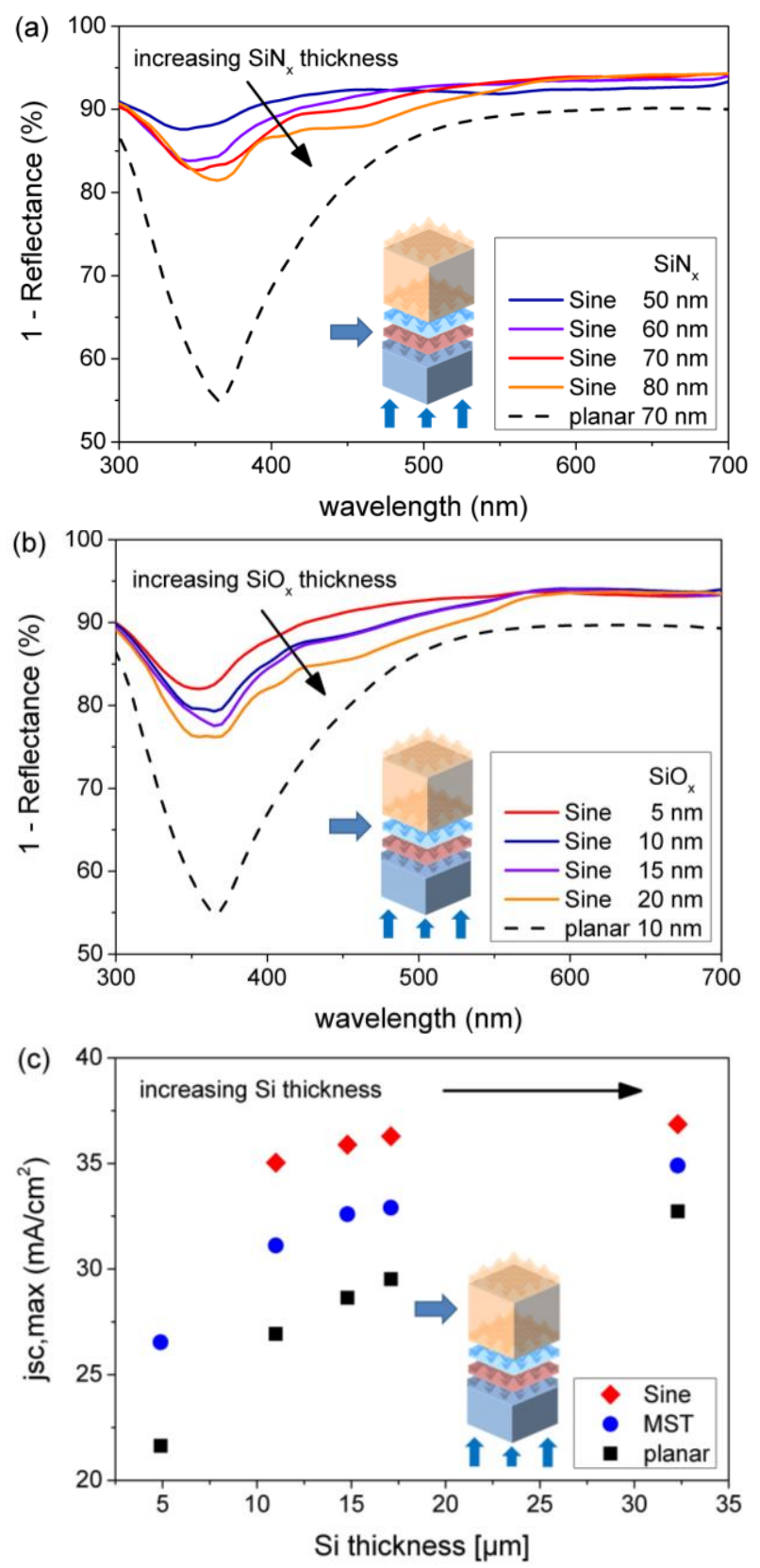

Fig. 3. Reflectance data (plotted as 1-R) of (a) $\mathrm{SiN}_{\mathrm{x}}$ and (b) $\mathrm{SiO}_{\mathrm{x}}$ interlayer thickness variations representatively shown on the sinusoidal texture (solid lines) in comparison to a planar reference (dashed line). The actual thicknesses of the varied $\mathrm{SiN}_{\mathrm{x}} / \mathrm{SiO}_{\mathrm{x}}$ layer are given in the figure. (c) Maximum achievable short-circuit current density $\left(j_{s c, \max }\right)$ of planar references (black, square), randomly MST textured (blue, circle) as well as sinusoidal textured (red, diamond) as a function of silicon absorber layer thickness.

MST (circle, blue) textured substrates to a planar reference device (square, black), the maximum achievable short-circuit current density $\left(j_{s c, \max }\right)$ has been calculated based on the measured absorption data assuming that every incident photon generates an electron-hole pair using 


$$
j_{s c, \max }=e \int_{280 \mathrm{~nm}}^{1100 \mathrm{~nm}} \frac{S(\lambda)}{h \nu} A(\lambda) d \lambda
$$

where $e$ represents the elementary charge, $h v$ the photon energy, $S(\lambda)$ the spectral intensity under AM1.5g and $A(\lambda)$ the measured absorption.

For all texture types $j_{s c, \max }$ rises with increasing silicon absorber layer thickness since the light path inside the absorber layer increases allowing for more electron-hole pairs to be generated. However, for processing time and cost reasons the silicon absorber layer should be chosen as thin as possible. The data point at $5 \mu \mathrm{m}$ of the sinusoidal texture is missing because this sample delaminated during the LPC process. Nevertheless, independent of the silicon thickness, using a double-sided textured absorber layer increases absorption. For thicker layers this enhancement is less pronounced because with rising amount of light being already absorbed in the silicon absorber layer the amount of light being left to be scattered at the rear side declines. In addition, the rear side texture of the double-side textures smoothens with increasing amount of silicon being deposited on top of the textured substrate reducing the scattering ability of the structures. For all thicknesses the absorption enhancement is more pronounced for the sinusoidal texture (diamond, red) than for the MST texture (circle, blue).

For further experiments a silicon thickness of $15-\mu \mathrm{m}$ has been selected, where the MST texture enhances the maximum achievable short-circuit current density $\left(j_{s c, \max }\right)$ of the planar reference of $28.6 \mathrm{~mA} / \mathrm{cm}^{2}$ by $+4.0 \mathrm{~mA} / \mathrm{cm}^{2}$ and the sinusoidal texture by $+7.3 \mathrm{~mA} / \mathrm{cm}^{2}$.

In summary, based on the results presented in this section, interlayer thicknesses of $\mathrm{SiN}_{\mathrm{x}} 70 \mathrm{~nm} / \mathrm{SiO}_{\mathrm{x}} 5 \mathrm{~nm}$ and an absorber layer thickness of $15 \mu \mathrm{m}$ have been chosen for further processing and analysis regarding their optical (section B) and opto-electric (section C) properties. The corresponding schematic sample stack is depicted in Fig. 1a.

\section{B. Optical Properties of Optimized Textured LPC Si Absorber Layers}

The optical properties of the optimized LPC-Si absorber layer are depicted in Fig. 4.

For wavelengths shorter than $600 \mathrm{~nm}$ both texture types reduce average reflection losses (Fig. 4a, reflectance data, dashed lines) from $20.7 \%$ for the planar case (black) down to $16.8 \%$ for the MST sample (blue) and $11.3 \%$ for the sinusoidal sample (red), respectively. This reduction in reflection losses as well as light scattering at the rear side of the absorber layer are translated into an absorption enhancement over the entire wavelength range (solid lines). The corresponding maximum achievable short-circuit current density enhancement is depicted in Fig. 3c.
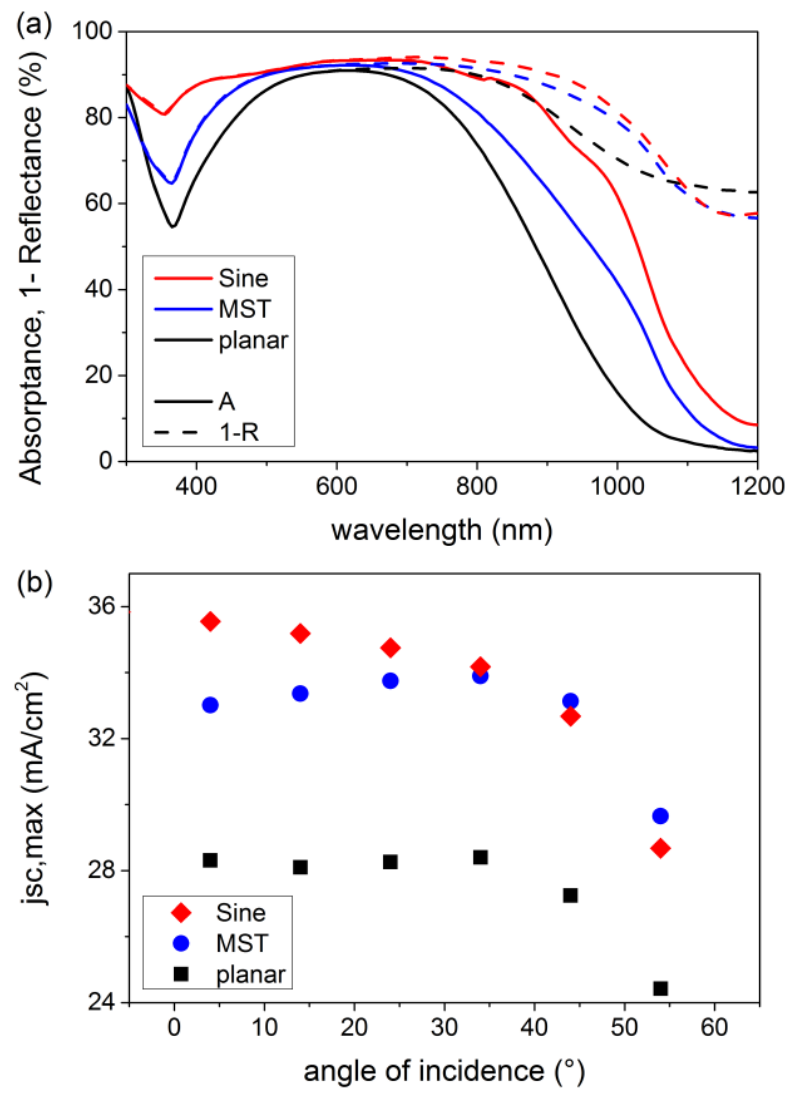

Fig. 4. Comparison of an absorber layer deposited on a planar (black) substrate and on a MST (blue) as well as on a sinusoidal (red) texture. (a) Absorptance (solid lines) and reflectance (dashed lines, plotted as 1-R) as well as (b) absorptance behavior under different incident angles of light are shown.

For wavelength larger than the band gap of silicon at around $1100 \mathrm{~nm}$ absorptance is still present for the sinusoidal texture being a hint for defect absorption and, hence, a lower material quality compared to the planar and MST textured device. On the contrary, the remaining absorption of about $2.5 \%$ at $1200 \mathrm{~nm}$ of the planar and MST textured samples can be attributed to imperfections of the integrating sphere like opening slits for detectors and incident light. At these long wavelengths reflection losses are more pronounced for textured devices than for the planar reference because light reaching the rear side of the double-sided textured absorber layer is scattered into higher angles and can partially escape through the side walls of the glass substrate and thus, contributes to the measured reflectance.

For usage in a solar cell device the optical behavior under different angles of light (Fig. $4 \mathrm{~b}$ ) plays a crucial role. For comparison $j_{s c \text {, max }}$ has been calculated according to (1) based on the measured absorption spectra for every angle of incidence. While absorptance in the sinusoidal textured absorber layer (red, diamond) declines with increasing angle of incidence, absorption in the MST textured layer (blue, circle) increases. The decline for the sinusoidal texture can be 
explained by small differences in refractive index between glass substrate, sol-gel and interlayers [22].

Absorptance of the planar reference (black) stays constant until an incident angle around $40^{\circ}$, for which all structure types start to decline strongly.

Further enhancement of the optical properties should be possible by using a different texture with larger pitch on the rear side of the absorber layer in order to optimize the rear side for light-trapping while keeping the glass-silicon interface texture optimized for anti-refection [23]-[25].

\section{Opto-electric Properties of Textured LPC Si Solar Cells}

Thin-film solar cell devices have been prepared using the optimized layer thicknesses found in section A (depicted in Fig. 1a) and are analyzed in Fig. 5. The data for the sinusoidal structure is missing because the sample delaminated during liquid phase crystallization. An analysis of the corresponding electronic properties prior to optimization can be found in [12]

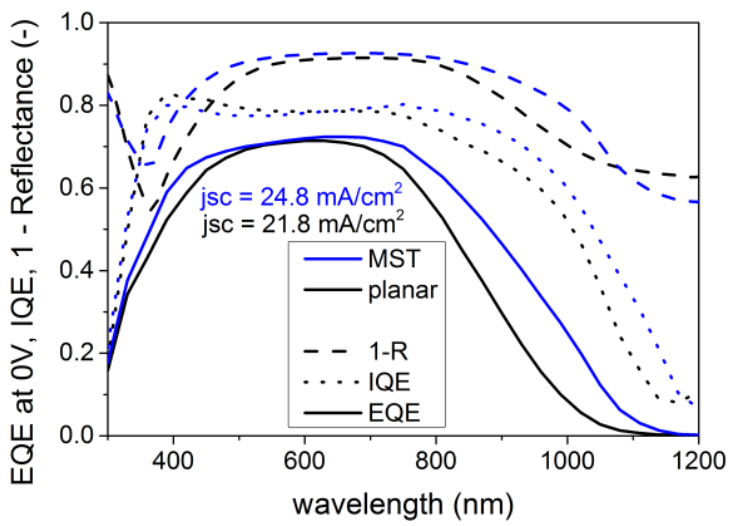

Fig. 5. Opto-electrical properties of a planar reference cell (black) and a MST textured cell (blue): Reflectance (dashed lines, plotted as 1-R), internal quantum efficiencies (IQE $=\mathrm{EQE} / \mathrm{A}$, dotted lines) and external quantum efficiencies (EQE, solid lines) with corresponding short-circuit current densities $\left(\mathrm{j}_{\mathrm{sc}}\right)$.

In Fig. 5 the external quantum efficiencies of a planar reference (black) and a MST textured device (blue) are compared. The MST textured device outperforms or is equal to the planar reference over the entire wavelength range resulting in a short-circuit current density $\left(j_{s c}\right)$ enhancement of $+3.0 \mathrm{~mA} / \mathrm{cm}^{2}$. Comparing the electrical properties (solid lines) to the optical properties (dashed lines, also shown in Fig. 4a) it is found that this enhancement can be attributed to the optical absorption enhancement resulting from the MST texture. Differences between $j_{s c, \text { max }}$ calculated from absorptance spectra (Fig. 3c) and electrically measured $j_{s c}$ (Fig. 5) can be attributed to electronic losses in the absorber layer and correspond to a loss of $-6.8 \mathrm{~mA} / \mathrm{cm}^{2}$ for the planar device and $-7.8 \mathrm{~mA} / \mathrm{cm}^{2}$ for the MST textured device. This result indicates that the material quality of the MST textured silicon absorber layer is almost as good as the material quality of the planar absorber layer. This conclusion is assisted by comparing the internal quantum efficiencies (IQE, dotted lines, calculated by dividing EQE (Fig. 5) by Absorptance (Fig. 4a) being comparable or slightly lower for wavelength shorter than $700 \mathrm{~nm}$ before light trapping at the rear side starts to play a crucial role.

In fact, comparing the open-circuit voltages averaged over the best five cells obtained on an planar and a MST textured substrate, the value obtained on the planar reference lies at $(643 \pm 6) \mathrm{mV}$ while on the MST texture an average value of $(630 \pm 4) \mathrm{mV}$ is obtained. The lower $\mathrm{V}_{\mathrm{oc}}$-values on the textured substrate may be explained by differences in $\mathrm{SiO}_{\mathrm{x}}$ layer thickness, since a substrate texture increases the surface area on which the layer is deposited. Hence, if the same amount of $\mathrm{SiO}_{\mathrm{x}}$ is deposited on a planar and a textured substrate, the $\mathrm{SiO}_{\mathrm{x}}$ layer is thinner and, as only $5-\mathrm{nm} \mathrm{SiO}_{\mathrm{x}}$ were nominally deposited, the $\mathrm{SiO}_{\mathrm{x}}$ may even be not closed everywhere across the surface, causing a drop in $\mathrm{V}_{\text {oc }}$ [20]. Furthermore, the standard deviation is related to the uniformity of the material quality over the substrate area. A comparison of the standard deviations indicates again that the silicon material quality on the MST texture is comparable to the quality obtained on a planar reference despite that the silicon has been grown and crystallized on a textured substrate.

\section{CONCLUSION}

We successfully integrated nanoimprinted hexagonal sinusoidal and wet-etched random modulated surface (MST) textures into liquid phase crystallized (LPC) silicon thin-film solar cells. The optical properties of both textures exceed the optimized planar reference cell over the entire wavelength range, which can be attributed to anti-reflective and light scattering effects of the double-sided textured silicon absorber layers grown on textured substrate. In addition, the influence of the $\mathrm{SiN}_{\mathrm{x}} / \mathrm{SiO}_{\mathrm{x}}$ interlayers as well as the silicon absorber layer thickness on reflectance has been studied and optimized thicknesses for $\operatorname{SiN}_{\mathrm{x}}(70 \mathrm{~nm}), \mathrm{SiO}_{\mathrm{x}}(5 \mathrm{~nm})$ and silicon $(15 \mu \mathrm{m})$ have been found. Optimized devices have also been studied regarding their optical and opto-electrical properties. In the wavelength range between $300 \mathrm{~nm}$ and $600 \mathrm{~nm}$ average reflectance could be reduced by $9.4 \%$ (absolute) using a sinusoidal texture. For the MST texture, the optical advantages could directly be transferred into an enhanced external quantum efficiency rising the short-circuit current density by $+3 \mathrm{~mA} / \mathrm{cm}^{2}$. Average open-circuit voltages of $630 \mathrm{mV}$ and $643 \mathrm{mV}$ were obtained for MST textured and planar cells, respectively. Those results indicate that the high material quality of LPC-Si on planar substrates can be transferred to wet-etched MST substrates. Therefore, our results demonstrate the suitability of textured glass substrates for promising future LPC silicon thin-film solar cell designs. 


\section{ACKNOWLEDGEMENT}

The authors gratefully acknowledge the support of M. Krüger and H. Rhein, Helmholtz-Zentrum Berlin, in solar cell preparation. The German Federal Ministry of Education and Research (BMBF) is acknowledged for funding the research activities of the Young Investigator Group 'NanoSIPPE' at HZB in the program NanoMatFutur (no. 03X5520).

\section{REFERENCES}

[1] T. Frijnts, S. Kühnapfel, S. Ring, O. Gabriel, S. Calnan, J. Haschke, B. Stannowski, B. Rech, and R. Schlatmann, "Analysis of photo-current potentials and losses in thin film crystalline silicon solar cells," Sol. Energy Mater. Sol. Cells, vol. 143, pp. 457-466, Dec. 2015.

[2] M. Despeisse, C. Battaglia, M. Boccard, G. Bugnon, M. Charriere, P. Cuony, S. Haenni, L. Loefgren, F. Meillaud, G. Parascandolo, T. Soederstroem, and C. Ballif, "Optimization of thin film silicon solar cells on highly textured substrates," Phys. Status Solidi A, vol. 208, no. 8, pp. 1863-1868, Aug. 2011.

[3] B. Liu, X. Liang, J. Liang, L. Bai, H. Gao, Z. Chen, Y. Zhao, and $X$. Zhang, "Broadband light trapping based on periodically textured $\mathrm{ZnO}$ thin films," Nanoscale, vol. 7, no. 21, pp. 98169824, 2015.

[4] V. E. Ferry, M. A. Verschuuren, M. C. van Lare, R. E. I. Schropp, H. A. Atwater, and A. Polman, "Optimized spatial correlation for boradband light trapping nanopatterns in high efficiency ultrathin film a-Si:H solar cells," Nano Lett., vol. 11, pp. 4239-4245, 2011.

[5] C. Haase and H. Stiebig, "Thin-film silicon solar cells with efficient periodic light trapping texture," Appl. Phys. Lett., vol. 91, no. 6, p. 061116, Aug. 2007.

[6] C.-M. Hsu, C. Battaglia, C. Pahud, Z. Ruan, F.-J. Haug, S. Fan, C. Ballif, and Y. Cui, "High-Efficiency Amorphous Silicon Solar Cell on a Periodic Nanocone Back Reflector," Adv. Energy Mater., vol. 2, no. 6, pp. 628-633, 2012.

[7] M. Sever, J. Krč, and M. Topič, "Prediction of defective regions in optimisation of surface textures in thin-film silicon solar cells using combined model of layer growth," Thin Solid Films, vol. 573, pp. 176-184, 2014

[8] V. Jovanov, U. Planchoke, P. Magnus, H. Stiebig, and D. Knipp, "Influence of back contact morphology on light trapping and plasmonic effects in microcrystalline silicon single junction and micromorph tandem solar cells," Sol. Energy Mater. Sol. Cells, vol. 110, pp. 49-57, 2013.

[9] H. Tan, E. Psomadaki, O. Isabella, M. Fischer, P. Babal, R. Vasudevan, M. Zeman, and A. H. M. Smets, "Micro-textures for efficient light trapping and improved electrical performance in thin-film nanocrystalline silicon solar cells," Appl. Phys. Lett., vol. 103, no. 17, p. 173905, 2013.

[10] H. Sai, K. Saito, N. Hozuki, and M. Kondo, "Relationship between the cell thickness and the optimum period of textured back reflectors in thin-film microcrystalline silicon solar cells," Appl. Phys. Lett., vol. 102, no. 5, pp. 53505-53509, 2013.

[11] V. Preidel, D. Amkreutz, J. Haschke, M. Wollgarten, B. Rech, and C. Becker, "Balance of optical, structural, and electrical properties of textured liquid phase crystallized Si solar cells," $J$.
Appl. Phys., vol. 117, no. 22, p. 225306, Jun. 2015.

[12] G. Köppel, B. Rech, and C. Becker, "Sinusoidal nanotextures for light management in silicon thin-film solar cells," Nanoscale, vol. 8, no. 16, pp. 8722-8728, 2016.

[13] O. Isabella, J. Krč, and M. Zeman, "Modulated surface textures for enhanced light trapping in thin-film silicon solar cells," Appl. Phys. Lett., vol. 97, no. 10, p. 101106, 2010.

[14] G. Yang, R. a. C. M. M. van Swaaij, H. Tan, O. Isabella, and M. Zeman, "Modulated surface textured glass as substrate for high efficiency microcrystalline silicon solar cells," Sol. Energy Mater. Sol. Cells, vol. 133, pp. 156-162, Feb. 2015.

[15] G. Köppel, D. Amkreutz, P. Sonntag, G. Yang, R. Van Swaaij, O. Isabella, B. Rech, and C. Becker, "Facing the challenge of liquid phase crystallizing silicon on textured glass substrates," Proceedings of the $43^{\text {rd }}$ IEEE Photovoltaic Specialist Conference, Portland, 2016, to be published.

[16] O. Yang, G. · Van Swaaij, R.A.C.M.M. · Isabella, "WO2015093966A1.pdf," WO 2015093966 (A1).

[17] J. Dore, R. Evans, B. Eggleston, S. Varlamov, and M. A. Green, "Intermediate Layers for Thin-Film and Polycrystalline Silicon and Solar Cells and on Glass and Formed by Diode Laser Crystallization," in MRS Proceedings, 2012, vol. 1426, pp. 6368.

[18] I. Höger, M. Himmerlich, A. Gawlik, U. Brückner, S. Krischok, and G. Andrä, "Influence of intermediate layers on the surface condition of laser crystallized silicon thin films and solar cell performance," J. Appl. Phys., vol. 119, no. 4, p. 045306, Jan. 2016.

[19] C. Becker, V. Preidel, D. Amkreutz, J. Haschke, and B. Rech, "Double-side textured liquid phase crystallized silicon thin-film solar cells on imprinted glass," Sol. Energy Mater. Sol. Cells, vol. 135, pp. 2-7, Apr. 2015.

[20] D. Amkreutz, W. D. Barker, S. Kuhnapfel, P. Sonntag, O. Gabriel, S. Gall, U. Bloeck, J. Schmidt, J. Haschke, and B. Rech, "Liquid-Phase Crystallized Silicon Solar Cells on Glass: Increasing the Open-Circuit Voltage by Optimized Interlayers for n- and p-Type Absorbers," IEEE J. Photovoltaics, vol. 5, no. 6, pp. 1757-1761, Nov. 2015.

[21] D. Lockau, M. Hammerschmidt, J. Haschke, M. Blome, F. Ruske, F. Schmidt, and B. Rech, "A comparison of scattering and non-scattering anti-reflection designs for back contacted polycrystalline thin film silicon solar cells in superstrate configuration," in SPIE Proceedings, 2014, vol. 9140, no. 914006, p. 914006.

[22] K. Jäger, C. Barth, M. Hammerschmidt, S. Herrmann, S. Burger, F. Schmidt, and C. Becker, "Simulations of sinusoidal nanotextures for coupling light into c-Si thin-film solar cells," Opt. Express, vol. 24, no. 6, p. A569, Mar. 2016.

[23] K. X. Wang, Z. Yu, V. Liu, Y. Cui, and S. Fan, “Absorption Enhancement in Ultrathin Crystalline Silicon Solar Cells with Antireflection and Light-Trapping Nanocone Gratings," Nano Lett., vol. 12, no. 3, pp. 1616-1619, 2012.

[24] M. Z. Pakhuruddin, J. Dore, J. Huang, and S. Varlamov, "Effects of front and rear texturing on absorption enhancement in laser-crystallized silicon thin-films on glass," Jpn. J. Appl. Phys., vol. 54, no. 8S1, p. 08KB04, Aug. 2015.

[25] X. Meng, E. Drouard, G. Gomard, R. Peretti, A. Fave, and C. Seassal, "Combined front and back diffraction gratings for broad band light trapping in thin film solar cell," Opt. Express, vol. 20, no. S5, p. A560, 2012. 